\title{
Effect of Nutrition Education on Improving Knowledge and Practice Regarding IYCF among Mothers with 6-24 Months Children
}

\author{
Sanjay Kumar Dabhi ${ }^{1 *}$ and Indravati Rao ${ }^{2}$ \\ ${ }^{1}$ Professor, Govt. College of Nursing, New Civil Hospital, Surat, Gujarat, India \\ ${ }^{2}$ Principal, Govt. College of Nursing, New Civil Hospital, Surat, Gujarat, India
}

*Corresponding author: Sanjay Kumar Dabhi, Professor, Govt. College of Nursing, New Civil Hospital, Surat, Gujarat, India; Email: princess1012012001@yahoo.com

Received: November 20, 2021; Accepted: November 27, 2021; Published: December 03, 2021

\begin{abstract}
Food insecurity and poor infant and young child feeding (IYCF) practices contribute to under nutrition. Nutrition during early years of life is crucial for children to survive, grow and develop into healthy adults who can lead rewarding lives and productively contribute to their communities. Infant and Young Child Feeding (IYCF) is a critical component of care in childhood. It is a major determinant of short- and long-term health outcomes in individuals, and hence of social and economic development of communities and nations. Objective of the study was to assess effectiveness of nutritional education intervention on improving knowledge and practice regarding IYCF among mothers having 6-24 months children. A Quantitative research approach and Quasi experimental design were used in this study, convenient sampling method with 30 samples were participated in the study, data was collected by structured questionnaire and observational checklist. Data was analyzed by descriptive and inferential statistics. The finding of the study revealed that the mean post-test knowledge score was higher than mean pre-test knowledge score with the mean difference of 11.67 which revealed that nutritional education intervention was effective in terms of knowledge among mothers. The mean post-test practice score was higher than mean pretest practice score with the mean difference of 16.75 which revealed that mothers were doing correct practice after nutritional education.
\end{abstract}

Keywords: Nutrition education, Knowledge, Practice, IYCF, Weaning

\section{Introduction}

"Breastfeeding is warmth, nutrition and love all rolled into one. It is a mother's gift to herself, her baby and the earth." Food insecurity and poor infant and young child feeding (IYCF) practices contribute to undernutrition. Nutrition during early years of life is crucial for children to survive, grow and develop into healthy adults who can lead rewarding lives and productively contribute to their communities. The period from birth to two years of age is considered as a "critical window" of opportunity as during this period the foundation for healthy growth and development in later years is laid down. Thus, adequate nutrition through this period has been recognized as national and international priority [1] and Young Child Feeding (IYCF) is a critical component of care in childhood. It is a major determinant of short- and long-term health outcomes in individuals, and hence of social and economic development of communities and nations [2]. Realizing this need, World Health Organization (WHO) recommends that optimal nutrition practices for infants and children include early initiation of breastfeeding i.e. within one hour of birth, exclusive breastfeeding for the first six months of life, followed by the addition of nutritionally adequate, safe, and appropriate complementary foods with continuation of breastfeeding for one year and longer. ${ }^{3}$ However, even after constantly emphasizing the importance of implementing these recommendations, the nation fails to elevate the status of Infant and Child Feeding which is necessary for attaining a better and yielding future. Optimal nutrition and hearty feeding are imperative for healthy growth and development of infants and young children. Globally, more than one-third of childhood deaths are attributed to undernutrition, which is more prevalent in low- and lower-middleincome countries $[1,2]$. In India, the third National and Family Health Survey [3] indicated that $46 \%$ of children below the age of three were underweight, $38 \%$ were stunted, and $19 \%$ were wasted. India is a country of various cultures and traditions. A lot of the customs and practices have their effect on our health including infant feeding practices. By assessing the knowledge, attitude and practices of mothers regarding their child's feeding, an overview can be obtained about the areas which need modification and hence specific intervention strategies can be made to correct the same.

\section{Problem Statement}

A explorative study to assess effectiveness of Nutrition educational intervention on improving Knowledge and practice regarding IYCF among mothers with 6-24 months at New Civil Hospital, Surat.

\section{Objectives}

The objectives of the study were:

1. Assess existing knowledge and practice regarding IYCF among mothers with 6-24 months at New Civil Hospital, Surat 
2. Develop and implement nutrition educational intervention regarding IYCF among mothers with 6-24 months

3. Determine correlation between knowledge and practice on nutritional educational intervention regarding IVCF among mothers with 6-24 months at New Civil Hospital, Surat

4. Find out association between pretest knowledge and practice regarding IYCF among mothers with 6-24 months at New Civil Hospital, surat with selected socio demographic variables.

\section{Assumption}

- Mothers don't have enough knowledge regarding IYCF and not doing correct practice towards IYCF.

- Nutritional education intervention helpful for improvement of knowledge and practice regarding IYCF which will be highly significant for growth and development of child.

\section{Delimitation}

- The study was delimited only mothers those who are having 6- 24 months old child.

- Those who are available and willing to participate in study at the time of the data collection.

- Study was delimited to pediatric ward, New Civil Hospital Surat, Gujarat.

\section{Research Methodology}

- Research approach: Quantitative evaluative Research Approach was used to assess effectiveness of nutrition educational intervention.

- Research design: Quasi experimental research design with one group pretest post Design

- Research setting: New Civil Hospital Surat, Gujarat

- Sampling technique: Convenient non probability sampling technique.

- Sample size: 30 .

\section{Sampling Criteria}

\section{Inclusion Criteria}

- Mothers who are able to communicate in Gujarati and Hindi.

- Mothers who are willing to participate in the study.

- Mother of children under age group 6-24 months.

- Mothers who visited in New Civil Hospital, Surat

- Exclusion Criteria

- Mother who are not willing to participate.

- Mothers of children above age group of 6-24 months.

- Mothers who are not available at the time of data collection.

\section{Description of Data}

- Section-I: demographic variables of subject - age, religion, education, qualification, Occupation, income of the family, parity, types of family, any information regarding IYCF

- Section -II: Self structured knowledge questionnaire- total 30 questionnaires related to IYCF

- Section- III: Observational practice Checklist for IYCF

- Section -IV: develop nutritional educational intervention

Validity of data: Validated by ${ }^{1} 0$ experts in the field of nursing.

Reliability: The reliability of the tool was calculate by using Split half method and the value were $0.89,0.92$, respectively.

Ethics and consent: informed consent taken to all subject. Before conducting this study took permission from Medical Superitendentant, New civil Hospital, Surat.

\section{Results and Discussion}

- Considering correlation between mothers posttest knowledge score and posttest practice score was a statistically significant, moderate positive correlation between them $(r=0.52 \mathrm{P} \leq 01$. $)$

The association between post-test knowledge score and demographic variables Age, education and occupational status had association with their demographic data, and posttest practice score age, education, monthly income and parity had association with their demographical data (Tables 1 and 2).

The finding coincides with the findings that study on effect of nutrition education on knowledge, complementary feeding and hygiene practices of mothers with moderate acutely malnourished children in Uganda. Result of study was Mean scores for knowledge, dietary diversity, and meal frequencies were higher at end line compared to baseline $(P<0.001)$. Handwashing did not improve significantly $(P=0.183)$, while boiling water to enhance water quality improved $(P<0.001)$.

\section{Recommendation}

1. Train to the grass root health workers on IYCF policies of WHO and MoHFW GOI, stressing on the benefits of appropriate feeding practices by hospital, CHC, PHC, HWC and making these services universally available with IEC.

2. Health care personnel traditionally encourage mothers to breastfeed by giving knowledge regarding benefits of breast feeding to infants as well mothers.

3. Breast feeding may be affected by religious ideologies, therefore it must be modified behavior and attitude of the mothers by giving counseling by reinforcing the cultural and religious practices.

4. Use of local religious techniques can bring positive changes in the implementation of health programs. 
Sanjay Kumar Dabhi (2021) Effect of Nutrition Education on Improving Knowledge and Practice Regarding IYCF among Mothers with 6-24 Months Children

Table 1: Finding related to analysis of demographic variable of mothers.

\begin{tabular}{|c|c|c|c|}
\hline Sr. No. & Variables & Frequency & Percentage \\
\hline 1. & \begin{tabular}{|cc} 
Age (in years) \\
• & $18-23$ years \\
$\bullet$ & $24-29$ years \\
$\bullet$ & $30-35$ years \\
- & Above 35 years \\
\end{tabular} & $\begin{array}{l}09 \\
14 \\
06 \\
01\end{array}$ & $\begin{array}{l}30 \% \\
47 \% \\
20 \% \\
03 \% \\
\end{array}$ \\
\hline 2. & \begin{tabular}{|cl} 
Religious : & \\
$\bullet$ & Hindu \\
• & Muslim \\
• & Christian \\
& Others \\
\end{tabular} & $\begin{array}{l}20 \\
10 \\
00 \\
00\end{array}$ & $\begin{array}{c}66 \% \\
34 \% \\
- \\
-\end{array}$ \\
\hline 3. & \begin{tabular}{|cl} 
Education & \\
• & Illiterate \\
- & Primary education \\
- & Higher secondary \\
- & Graduate and more than \\
\end{tabular} & $\begin{array}{l}06 \\
12 \\
10 \\
02\end{array}$ & $\begin{array}{l}20 \% \\
40 \% \\
34 \% \\
06 \% \\
\end{array}$ \\
\hline 4. & \begin{tabular}{|cl} 
Occupation & \\
$\bullet$ & Housewife \\
$\bullet$ & Government job \\
$\bullet$ & Private job \\
- & Other \\
\end{tabular} & $\begin{array}{l}25 \\
00 \\
01 \\
04\end{array}$ & $\begin{array}{c}83 \% \\
- \\
04 \% \\
13 \% \\
\end{array}$ \\
\hline 5. & \begin{tabular}{|cl} 
Community & \\
$\bullet$ & Urban \\
$\bullet$ & Rural \\
\end{tabular} & $\begin{array}{l}17 \\
13 \\
\end{array}$ & $\begin{array}{l}57 \% \\
43 \% \\
\end{array}$ \\
\hline 6. & $\begin{array}{l}\text { Monthly Income (rupees) < 5000/- } \\
5000-10000 /- \\
10000-15000 /- \\
>15000 /-\end{array}$ & $\begin{array}{l}06 \\
18 \\
08 \\
00\end{array}$ & $\begin{array}{c}20 \% \\
53 \% \\
27 \% \\
- \\
\end{array}$ \\
\hline 7. & $\begin{aligned} \text { Parity } & \\
\cdot & 1^{\text {st }} \text { child } \\
\cdot & 2^{\text {nd }} \text { child } \\
\cdot & >3 \text { child }\end{aligned}$ & $\begin{array}{c}08 \\
12 \\
10 \\
\end{array}$ & $\begin{array}{l}27 \% \\
40 \% \\
33 \% \\
\end{array}$ \\
\hline 8. & $\begin{aligned} & \text { Family } \\
& \bullet \text { Nuclear family } \\
& \bullet \text { Joint family } \\
&\end{aligned}$ & $\begin{array}{l}16 \\
14 \\
\end{array}$ & $\begin{array}{l}53 \% \\
47 \%\end{array}$ \\
\hline 9 & $\begin{array}{cl}\text { Source of information regarding IYCF } \\
\text { - } & \text { Journals and magazine } \\
\text { • } & \text { Social Media } \\
\text { - } & \text { T.V and Radio } \\
& \text { Any others }\end{array}$ & $\begin{array}{c}8 \\
16 \\
6 \\
-\end{array}$ & $\begin{array}{l}27 \\
53 \\
20 \\
-\end{array}$ \\
\hline
\end{tabular}

Table 2: Comparison of pretest and posttest knowledge and practice score regarding IYCF.

\begin{tabular}{|l|c|c|c|c|c|}
\hline \multirow{2}{*}{ Variables } & \multicolumn{2}{|c|}{ Pretest $(\mathrm{n}=\mathbf{3 0})$} & \multicolumn{2}{c|}{ Posttest (n=30) } & Mean Difference \\
\cline { 2 - 6 } & Mean score & Standard Deviation & Mean score & Standard Deviation & 2.04 \\
\hline Knowledge & 15.26 & 2.41 & 26.93 & 11.67 & 2.21 \\
\hline Practice & 29.46 & 2.99 & 46.21 & 16.75 \\
\hline
\end{tabular}

5. Government and other partners working on sustainable child nutrition reduction should focus on the nutrition education to improve the knowledge and appropriate complementary feeding practice including daycare centers [4-8].

\section{Conclusion}

Nutrition Education intervention was effective on improving knowledge and practice regarding IYCF. Its improved knowledge of mothers and they were doing correct practice of IYCF.

\section{References}

1. UNICEF/WHO/World Bank. Levels and Trends in Child Malnutrition: Key Findings of the 2019 Edition of the Joint Child Malnutrition Estimates. Geneva, Switzerland: World Health Organization; 2019.

2. WHO (2000) Effect of breastfeeding on infant and child mortality due to infectious diseases in less developed countries: a pooled analysis. Collaborative Study Team on the role of breastfeeding on the prevention of infant mortality. Lancet 355: 451-455. [crossref]

3. Dewey KG, Vitta BS (2013) Strategies for Ensuring Adequate Nutrient Intake for Infants and Young Children during the Period of Complementary Feeding. Washington, DC, USA: Alive \& Thrive. 
Sanjay Kumar Dabhi (2021) Effect of Nutrition Education on Improving Knowledge and Practice Regarding IYCF among Mothers with 6-24 Months Children

4. Beyene S, Willis MS, Mamo M, Belaineh L, Teshome R, Tsegaye T, et al. (2019) Nutritional status of children aged $0-60$ months in two drought-prone areas of Ethiopia. South African Journal of Clinical Nutrition.

5. Jukes M, McGuire J, Method F, Sternberg R Nutrition: a Foundation for Development. Geneva, Switzerland.

6. Drake L, Maier C, Jukes M, et al. (2002) School-age children: their nutrition and health. Partnership for Child Development 25: 4-30.
7. Hoddinott J, Alderman H, Behrman JR, Haddad L, Horton S (2013) The economic rationale for investing in stunting reduction. Maternal \& Child Nutrition 9: 69-82. [crossref]

8. Black RE, Morris SS, Bryce J (2003) Where and why are 10 million children dying every year? Lancet 361: 2226-2234. [crossref]

\section{Citation:}

Dabhi SK, Rao I (2021) Effect of Nutrition Education on Improving Knowledge and Practice Regarding IYCF among Mothers with 6-24 Months Children. Integr J Nurs Med Volume 2(4): 1-4. 